\title{
Organizing a grazing route to motivate intake on coarse resources
}

\author{
$M$ Meuret \\ INRA-SAD, Ecodéveloppement, Domaine Saint-Paul, Site Agroparc, F 84914 Avignon, France
}

Within a single day, a herd out to graze in Provence may well come across extremely diverse vegetation (old pastures, wildlands, shrublands and underbrush). Landscape is composed of a constellation of small pieces of lands. Today, rural population have foresaken these lands, that still bears visible traces of the role they played in times of old (Hubert et al, Proc Vth Intern Rang Cong, 1995, in press). Irregular soils and varying degrees of shade are but some of the factors that contribute to the diversity of plant communities. The response of a herd that meanders through such a patchy environment is to develop selective, opportunist behaviour (Cézilly et al, 1991, Acta Ecologica, 12, 683-696).

How does the herder respond to such behaviour? Rather than trying to inhibit this selective behaviour (by regularly providing the most high quality feed), he tries to identify trends in order to be able to influence the behaviour in a way that ensures both animal performances objectives and farm resources sustainability (Meuret, 1993, Etu et Rech SAD, $27,161-198)$. The question is how to use the foreseeable behavioural response as a "tool", to impact the herd-space relationship and thus be able to better control the nature and sites of animal intake. From this vantage point it is less useful for research to work out the "animal" effect or the "feed" effect, because the main tools in conditionning animal behaviour come from the triangular "herd-herder-territory" relationship. Herding is a typical multivariate and interactive feeding process :

- Criteria used in animal selection are not only based on production levels and the capacity to respond well to changes in diet, but also on the animal's capacity to become part of the social life of the herd, in other words, to meet the herder's expectations in animal behaviour trends.

- Feed is of very varied nutritional value and palatability. Furthermore, it changes with the seasons. Since it is generally impossible (or very rarely possible) to "improve" such feed, the answer will lie in the ability to enhance the animal's motivation to consume it.

- As for the herders, there is an uinternal selection (or elimination) process" that depends on their enthusiasm and motivation for producing animals in places where conditions are frequently uncertain and where their skills as observers and experimenters have to play a major role in feeding process. In any case, none of the situations we found in the grazing lands in Provence are covered by the known feed intake prediction models: intake is very high (> $100 \mathrm{~g} \mathrm{DM} / \mathrm{kgLW} 0.75 / \mathrm{day}$ ) even in the range of low digestibility values (40 to $60 \%$ OMd). Trials under controlled conditions confirmed that animals, which were used to consuming rough, heterogeneous herbage, from a very tender age (Meuret, 1988, Small Rumin Res, 1, 273-290), could compensate for poor nutritional value by very high intake (Meuret and Giger-Reverdin, 1990, Reprod Nutr Dev, suppl 2, 205). This was proven allthemore true since the animals were left free to develop a feeding pattern in which the feed rejection rate was above the $10 \%$ usually recommended to ensure ad libitum conditions in the experimental procedures.

Our current application model requires focus on the kinetics of feed intake as animals trek the grazing route. It is the outcome of observations of 30 3-hour meals consumed by dairy goats at pasture within a mixed Quercus pubescens coppice and grasslands area (Meuret and Bruchou, 1994, Renc Rech Rumin, 1, 225-228). The diversity of dietary choices did affect total intake. We can model a relation between this total intake and the difference in choices between plant species at different times along the route. The model adjustement shows an optimal number of choosen plant species, that varies greatly at the beginning of the route, and stabilizes after 60 minutes. Too little diversity does not provide enough stimulation and too much diversity also inhibits intake, since the animal wastes time trying to find alternative eating items during the meal. The first hour on the route probably corresponds to the lapse of time which the 
animal can perceive and memorise the range of choices for the day. According to our model, it is reasonable to assume that at the end of the first hour the animal has reached a point of balance between the physiological feeling of hunger and the desire for new items in an environment that offers choices.

Animal producers who have developed their own savoir-faire in herd management have often said that the conditions at the beginning of the route are very important in motivating herd appetite. The global model on route design, based from on-farm surveys, shows that there are two modes in the start up phase, and that they depend on the initial apparent appetite of the herd. This model, which draws on the "menu" concept in a restaurant (see Meuret, 1993), is based on two rules:

1/ Creation of synergetic sequences: the purpose is to organise herds so that they tread on a series of plots whose resources are of different degrees of palatability, in an order that stimulates intake. The herders divide their territory into different zones, each of which has one of the following six roles: appetite promotion, moderation, main course, booster, second course, dessert. These specific areas generally offer a combination of plant communities. They are identified for each season, inter alia, according to the foreseeable abundance of consumable feed and their relative palatability. If the grazing route is well designed, the herd's feeding motivation can be oriented to optimise on the less palatable feed resources, which are the most frequently of limited supply. The extent of the herder's skill depends on his control of the frequency of encountering new resources and the frequency of access to clearly preferred resources.

2/ Ride the trend: the herder's decision to exploit a new zone on the route is usually based on his observation of herd attitude. $\mathrm{He}$ will try to avoid going against spontaneous trend. An analysis of the herder's treatment of his animals shows that he prefers to strictly limit the number of his interventions (Meuret et al, 1994, Ann Zoot, 43, 296). He usually restricts himself to changing the pace and direction of herd movement. This means that the animals will graze on more diversified areas than if they were left on their own. The herd develops confidence in the herder. This is especially noteworthy when the circuit is composed of successive "loops". The herd spontaneously returns to the herder to get new "travel order".

The concept of routes, or circuits, imparts meaning to plant communities marked by diversity. Using rules derived from the systematic observation of animal behaviour, the herder develops a mental image of his territory as a series of units that could become complementary. The resulting new pastoral maps refer to the "useful diversity" of a territory which pools together seemingly heterogeneous areas (because of microclimates, topography, plant communities and species, etc.) into homogeneous zones marked by a sequence that contributes to increasing the herd's dietary motivations. 